\title{
Aa. Vv., Les Amériques des écrivains français
}

\section{Pierangela Adinolfi}

\section{(2) OpenEdition}

\section{Journals}

\section{Edizione digitale}

URL: http://journals.openedition.org/studifrancesi/3915

DOI: $10.4000 /$ studifrancesi.3915

ISSN: 2421-5856

\section{Editore}

Rosenberg \& Sellier

\section{Edizione cartacea}

Data di pubblicazione: 1 décembre 2012

Paginazione: 624-625

ISSN: 0039-2944

\section{Notizia bibliografica digitale}

Pierangela Adinolfi, «Aa. VV., Les Amériques des écrivains français», Studi Francesi [Online], 168 (LVI | III) | 2012, online dal 30 novembre 2015, consultato il 06 mars 2021. URL: http://journals.openedition.org/ studifrancesi/3915 ; DOI: https://doi.org/10.4000/studifrancesi.3915

Questo documento è stato generato automaticamente il 6 mars 2021.

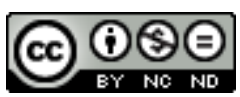

Studi Francesi è distribuita con Licenza Creative Commons Attribuzione - Non commerciale - Non opere derivate 4.0 Internazionale. 


\title{
Aa. Vv., Les Amériques des écrivains français
}

\author{
Pierangela Adinolfi
}

\section{NOTIZIA}

AA. VV., Les Amériques des écrivains français, in «Travaux de Littérature» XXIV, publiés par l'ADIREL avec le concours du «Centre national du livre», Genève, Droz, 2011, pp. 398.

1 Il volume riunisce trentuno studi inerenti alla rappresentazione della mitologia americana nelle opere degli scrittori francesi. A partire dalla scoperta del continente americano compiuta dagli europei fino ai giorni nostri, le terre d'America, caratterizzate dalla loro lontananza e dal loro esotismo, hanno affascinato gli scrittori francesi, suggestionato la loro immaginazione e costituito una sorta di doppio negativo della vecchia Europa, oggetto di passione e talvolta di rifiuto. Le Americhe compaiono inizialmente nei «récits de voyage». Il campo d'indagine si estende da Jean de Léry a Jean-Paul Sartre, passando per Chateaubriand e Tocqueville, e scopre «récits»o «mémoires», inediti o poco studiati, come quelli degli esploratori del fiume Orinoco. La mitologia americana s'incarna in alcuni "tipi", per esempio il self-made man, «l'oncle d'Amérique», «l'Indien féroce», «la belle américaine», «le sauvage brésilien sans dieux ni lois». Le Americhe forniscono anche il pretesto per sviluppare grandi dibattiti ideologici come quelli riguardanti i Gesuiti del Paraguay o l'antiamericanismo nella letteratura francese del secolo scorso.

2 All' «Introduction» di Sylvain MENANT (pp. 7-11) fanno seguito gli ulteriori studi: Adrien PASCHOUD, «Les sacralités amérindiennes au prisme de l'écriture pré-ethnographique: l'exemple de Jean de Léry» (pp.13-24); Marie-Christine PIOFFET, «La Nouvelle-France dans les écrits de Cartier et de Champlain: de la dénégation au "descouvrement"» (pp. 25-38); Amelia SANZ, "Présences in absentia: les Amériques du XVII ${ }^{\mathrm{e}}$ siècle» (pp. 39-54); Jacques CORMIER, «Les Amériques de Robert Challe» (pp. 55-64); François MOUREAU, «L'Amérique n'a aucun avenir: les idées “philosophiques” de Cornelius De 
Pauw» (pp. 65-80); Sylviane ALBERTAN-COPPOLA, «Les Américaines dans l'Histoire générale des Voyages de l'abbé Prévost» (pp. 81-91); Girolamo IMBRUGLIA, «Entre utopie et histoire: Montesquieu et le Paraguay» (pp. 93-103); Frédéric DOREL, «L'histoire de l'Amérique au cœur des passions françaises: le cas du Paraguay» (pp. 105-116); Letizia NORCI CAGIANO, «Élèves en France et néophytes au Paraguay. L'éducation des gésuites à travers les Lettres édifiantes envoyées d'Amérique du Sud (1700-1740)» (pp. 117-128); Marie-Laure GIROU-SWIDERSKI, "Être péruvienne ou ne pas être: la Zilia de Mme de Graffigny» (pp. 129-141); Jérôme BRILLAUD, «Les Veuves créoles et le théâtre à la Martinique au XVIII ${ }^{\mathrm{e}}$ siècle» (pp.143-152); Laurent VERSINI, «Diderot et la nouvelle Athènes américaine» (pp. 153-159); John RENWICK, «Les Incas de Marmontel, sources et enjeux: un philosophe lit les historiens et les voyageurs» (pp. 161-172); Adriana CABRERA, «Les voyageurs français et le fleuve Amazone» (pp.173-183); Emmanuelle TABET, «Mémoires du Nouveau Monde: du Voyage en Amérique aux Mémoires d'outre-tombe de Chateaubriand» (pp. 185-194); David scoTT, «De la démocratie à Disneyland: les États-Unis comme utopie d'après Tocqueville et Baudrillard» (pp. 195-206); Amilcar TORRAO FILHO, «Le catholicisme luso-brésilien selon les voyageurs français du XIX siècle» (pp. 207-217); Frank LeSTRINGANT, «Ferdinand Denis, inventeur de la France Antarctique du Brésil» (pp. 219-234); Isabelle Guillaume, «Les métamorphoses de l'oncle d'Amérique (18261918)» (pp. 235-244); Nirina RALANTOARITSIMBA, «Le self-made man californien» (pp. 245-254); Denis PERNOT, «Outre-Mer de Paul Bourget, une expérience littéraire américaine» (pp. 255-264); Philippe ROGER, «Scènes de la vie funèbre: l'Amérique de Georges Duhamel» (pp.265-274); Jérôme NEUTRES, «New York: ville américaine, mythologie française» (pp. 275-286); Antoinette WEBER-CAFLISCH, «L'Amérique dans l'œuvre dramatique de Paul Claudel» (pp. 287-304); Monique GOSSELIN-NOAT, «Bernanos et le Brésil» (pp. 305-318); Ralph HEYNDELS, «Les Noirs sur la blancheur livide: le sens possible de l'Amérique selon Genet» (pp.319-331); Yan HAMEL, «Un touriste engagé, Jean-Paul Sartre écrit l'Amérique» (pp. 333-343); Arthur TANG, «Le Brésil romanesque de Conrad Detrez: à rebours d'une tradition réductive» (pp.345-353). Pierre-Louis REY, «L'Amérique des romanciers français (1930-1960)» (pp.355-369). Negli «Annexes» troviamo Florence LIGNAC et Roger MUSNIK con, «L'Amérique, la France et la Bibliothèque» (pp.371-379). L'Indice dei nomi e l'elenco dei profili degli autori dei contributi chiudono il volume. 